\title{
OS SABERES DE FORMAÇÃO DO/A PEDAGOGO/A NO ATEN- DIMENTO ESCOLAR À CRIANÇA HOSPITALIZADA
}

\author{
THE KNOWLEDGE OF THE FORMATION OF A PEDAGOGUE ON SCHOOL AT- \\ TENDANCE OF A HOSPITALIZED CHILD

\section{LOS SABERES DE FORMACIÓN DEL PEDAGOGO EN EL ATENDIMIENTO ES- COLAR A LOS NIÑOS HOSPITALIZADOS}

\author{
Francy Sousa Rabelo \\ Professora Mestre da Universidade Federal do Maranhão (UFMA). \\ francy.rabelo@ufma.br \\ Silvina Pimentel Silva \\ Professora Doutora da Universidade Estadual do Ceará (UECE). \\ silvinapimentel@yahoo.com.br \\ Geandra Claúdia Silva Santos \\ Professora Doutora da Universidade Estadual do Ceará (UECE). \\ geandracss@yahoo.com.br
}

\begin{abstract}
RESUMO: Neste trabalho, empreendemos uma análise voltada para a constituição de saberes docentes na formação inicial do/a pedagogo/a, com base na experiência desenvolvida em espaço hospitalar. Tal pesquisa se configura do tipo estudo de caso, subsidiada em Stake (2007), Yin (2010) e André (2005). Os sujeitos da pesquisa são egressas do Curso de Pedagogia da Universidade Federal do Maranhão que participaram como bolsistas e voluntárias do projeto de extensão Estudar, uma ação saudável desenvolvido no Hospital Universitário da Universidade Federal do Maranhão. Os dados obtidos são frutos de entrevistas semiestruturadas, posteriormente organizadas, analisadas e interpretadas à luz de autores como Fonseca (2003), Tardif (2010) e Gauthier et al. (1998), dentre outros. Os resultados assinalam que o/a pedagogo/a em formação vivencie as especificidades dos espaços de trabalho diversos da educação escolar, conforme aponta as Diretrizes Curriculares de seu curso (BRASIL, 2006), como por exemplo, o hospital, e que os desafios desta atuação são superados pela constituição de saberes da formação profissional que evocam uma prática docente mais humanizada pela escuta sensível a partir das histórias de vidas dos sujeitos, seus gestos, suas palavras e seus comportamentos que se sucedem nas reações da hospitalização e da doença. Concluímos que o atendimento escolar da criança hospitalizada requer do/as professore/as uma formação que incorpore os debates acerca dos novos espaços de atuação do/a pedagogo/a e que incluam os subsídios para o exercício da docência em atividades diversas dentro e fora da escola.
\end{abstract}

PALAVRAS-CHAVE: Criança hospitalizada. Formação inicial. Pedagogo/a. Saberes docentes.

ABSTRACT: At this work, we have done an analysis focused on the constitution of teaching knowledge in the initial formation of a pedagogue, based on the developed experience in the hospital environment. Such research is configured as a case study, subsidized at Stake (2007), Yin (2010) and André (2005). The research subjects are graduates of the Pedagogy course of Maranhão State University, who participated as scholarship holders and volunteers of the extension project Estudar, uma ação saudável (Studying, a healthy action), developed at the University Hospital of Maranhão Federal University. The acquired data is the result of semi-structured interviews. It was subsequently organized, analyzed and interpreted in light of authors such as Fonseca (2003), Tardif (2010) and Gauthier et al. (1998), among others. The results show that the pedagogues in training experience the characteristics of different working areas of education, as shown by the Curriculum Guidelines of the course (BRAZIL, 2006), such as a hospital, and the challenges of this representation are outweighed by the constitution of knowledge on the professional formation, which evoke a more humanized teaching by the sensitive listening of the live stories of the subjects, their gestures, their words and behavior that follow the reaction to their hospitalization and disease. It is concluded that the school attendance of hospitalized children require from pedagogues a training that incorporates the discussion about the new spaces for their performance, that includes the subsidies for the exercise of teaching in various activities inside and outside of the schools.

KEYWORDS: Hospitalized children. Initial formation. Pedagogue. Teaching knowledge.

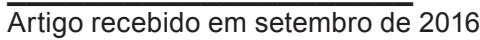

Aprovado em novembro de 2016 
RESUMEN: En este trabajo, emprendemos un análisis direccionada para la constitución de saberes docentes en la formación inicial del pedagogo o pedagoga, con base en la experiencia desarrollada en espacio hospitalario. Tal pesquisa se configura del tipo estudio de caso, subsidiada en Stake (2007), Yin (2010) y André (2005). Los sujetos de pesquisa son egresos del Curso de Pedagogía de la Universidad Federal do Maranhão que participaron como becarios y voluntarios del proyecto de extensión Estudiar, una acción saludable desarrollado en el Hospital Universitario de la Universidad Federal do Maranhão. Los dados obtenidos son frutos de entrevistas semi-estructuradas, posteriormente organizadas, analizadas y interpretadas a la luz de autores como Fonseca (2003), Tardif (2010) y Gauthier et al. (1998), entre otros. Los resultados señalan que el pedagogo o la pedagoga en formación tiene que vivir las especificidades de los espacios de trabajo diversos de la educación escolar, conforme apunta las Directrices Curriculares de su curso (BRASIL, 2006), como por ejemplo, el hospital, y que los desafíos de esta actuación son superados por la constitución de saberes de la formación profesional que evocan una práctica docente más humanizada por la escucha sensible a partir de historias de vidas de los sujetos, sus gestos, sus palabras, y sus comportamientos que se repiten en las reacciones de la hospitalización y de la enfermedad. Concluimos que el atendimiento escolar del niño hospitalizado requiere de los/ las profesores/as una formación que incorpore los debates acerca de los nuevos espacios de actuación del pedagogo o de la pedagoga y que incluyan los subsidios para el ejercicio de la docencia en actividades diversas dentro y fuera de la escuela.

PALABRAS CLAVE: Niño hospitalizado. Formación inicial. Pedagogo/a. Saberes docentes. 
OS SABERES DE FORMAÇÃO | Francy S. Rabelo, Silvina P. Silva e Geandra Claúdia S. Santos

\section{1| INTRODUÇÃO}

Em relação ao direito à educação de crianças hospitalizadas é esclarecedor destacar a Resolução no 41 do Conselho Nacional do Direito da Criança e do Adolescente, aprovada em 1995. Esta veio para garantir a esse segmento populacional o "direito de desfrutar de alguma forma de recreação, programas de educação para a saúde e acompanhamento do currículo escolar durante sua permanência hospitalar" (BRASIL, 1995, p. 1). Seu amparo se legitima na Lei $n^{\circ}$ 9.394/96 em seu art. 58, $\S 2^{\circ}$, quando estadeclara que o "atendimento educacional será feito em classes, escolas ou serviços especializados, sempre que, em função das condições específicas dos alunos, não for possível a sua integração nas classes comuns de ensino regular" (BRASIL, 2010, p. 44). Tal fato é ampliado pela Resolução CNE/CEB $n^{\circ}$ 02/2001, que instituiu as Diretrizes Nacionais para a Educação Especial na Educação Básica, no art. 13 (BRASIL, 2001b), em que favorece a criação de Classes Hospitalares.

Com o advento das classes hospitalares, manifesta-se a exigência de que o sistema educacional brasileiro e, mais especificamente, as propostas de cursos de formação em nível de graduação cumpram provocações na formação de professore/as para exercerem tarefas nessa área de atuação.

O estudo ora apresentado está situado no campo de formação de professore/as e aborda a constituição de saberes docentes na formação inicial do/a pedagogo/a e a experiência docente na educação não escolar no hospital; é vinculado à extensão universitária da Universidade Federal do Maranhão por meio do projeto Estudar, uma ação saudável: construindo uma pedagogia hospitalar.

É com inspiração nos estudos realizados na Dissertação de Mestrado de Rabelo (2014), e na legislação vigente que, neste texto, temos com objetivo discutir sobre os saberes constituídos pelo/as pedagogo/as em formação no espaço hospitalar. Tal objeto de estudo se justifica por entender que a formação do/a professor/a, especialmente em cursos de Pedagogia, agentes principais da Educação Infantil e dos Anos Iniciais do Ensino Fundamental, devem ocupar-se de suas atribuições com a educação não escolar, não apenas como foco do debate acadêmico, mas como conteúdo do seu projeto formativo. Diferentemente do que tem acontecido até então, ou seja, a prioridade da escola regular como campo de estudo e como lócus específico da atuação de tal profissional, estas análises nutrem-se da experiência realizada junto ao projeto de extensão já referenciado em parceria firmada entre o Curso de Pedagogia da Universidade Federal do Maranhão (UFMA) e o Hospital Universitário da Universidade Federal do Maranhão (HUUFMA).

A pesquisa referência caracteriza-se pela abordagem qualitativa, com resultados decorrentes do contato direto do/a pesquisador/a com os sujeitos dela participantes, definindo-se como de caráter descritivo. Ademais, assume atributos de um estudo de caso, oferecendo elementos para a interpretação/compreensão do fenômeno pesquisado (saberes docentes) com suporte nas experiências vivenciadas pelos sujeitos da pesquisa.

Este estudo se fundamenta em André (2005), Stake (2007) e em Yin (2010) ao retratar uma situação da vida real: a docência das alunas quando estas estiveram em processo de formação inicial no Curso de Pedagogia da UFMA e do hospital, lócus de desenvolvimento do projeto de extensão de que se trata. Os sujeitos da pesquisa foram cinco egressas do referido curso, cujo critério era sua participação no referido projeto como bolsistas e voluntárias e estivessem exercendo atividades docentes em sala de aula regular. Este critério foi estabelecido com a finalidade de se compreender a contribuição da docência decorrente da vivência em espaço hospitalar, como instrumentalizador da constituição de saberes incorporados em sua prática docente atual. Tais sujeitos foram caracterizados como EV- Egressa Voluntária e EB- Egressa Bolsista. 
Para a geração dos dados, optamos por utilizar a entrevista semiestruturada e a análise documental através dos cadernos de registros, relatórios e monografias defendidas por egressas da UFMA, participantes do projeto supracitado, cujas temáticas envolveram a experiência docente no hospital. Tais documentos fazem referência ao período de 2009 a 2012. A análise desses dados fora organizada e codificada, interpretada e discutida à luz de autores que nortearam à temática.

\section{2 | OS NOVOS ESPAÇOS DE ATUAÇÃO E A FORMAÇÃO DO/A PEDAGOGO/A: DESCO- BRINDO NOVOS SABERES}

A formação do pedagogo tem vivenciado ao longo de sua história, inúmeras discussões concernentes a sua identidade e atuação, o que recai sobre o debate em reformulações nas propostas curriculares para o Curso de Pedagogia, resultado de amplos movimentos liderados por entidades, como a Associação Nacional pela Formação dos Profissionais da Educação (ANFOPE), e que a partir da década de 90 enfatiza a ruptura da ideia de currículo mínimo que predominou na organização dos cursos de graduação, especialmente o da Pedagogia, para a defesa da base comum nacional, esta que:

\footnotetext{
[...]se configura como diretriz orientadora dos cursos de formação de professores com o propósito de definir, respeitada a autonomia das IES formadoras de professores, um corpo de conhecimento fundamental que não fosse traduzido como currículo mínimo para as licenciaturas. (ANFOPE, 2014, p. 14).
}

Segundo este documento, a concepção da base comum nacional tem como foco o reconhecimento dos profissionais da educação, para expressar a luta dos educadores contra a desvalorização da profissão, cuja condição formativa deve nortear-se por princípios, dentre os quais, o compromisso social, político e ético do educador com um projeto emancipador e transformador das relações sociais excludentes, relações estas estabelecidas nas experiências educativas não escolares e enfatizadas nas Diretrizes Curriculares Nacionais para o Curso de Pedagogia, através da Resolução CNE/CP n 01/2006 (BRASIL, 2006), quando esta abre possibilidades de discussões sobre a formação do pedagogo para atuar em espaços não escolares.

O movimento em prol de tais diretrizes, segundo Aguiar et al. (2006) tem seu marco importante em 1998, quando a Comissão de Especialistas desempenhou amplos debates para sua elaboração. Tal processo, em nível nacional, contou com as contribuições de entidades ANFOPE, Fórum Nacional dos Diretores das Faculdades/Centros/Departamentos de Educação das Universidades Públicas Brasileiras (FORUMDIR), Associação Nacional de Graduação e Pesquisa em Educação (ANPED), Centro de Estudo Educação e Sociedade (CEDES), Executiva Nacional dos Estudantes de Pedagogia, cuja elaboração das diretrizes foram encaminhadas para o Conselho Nacional de Educação (CNE) em 1999, o documento "[...] permaneceu, ao longo de oito anos, aguardando a definição e regulamentação de outros pontos ainda polêmicos com relação à formação, como o próprio curso normal superior, que até o momento não possui suas próprias diretrizes" (AGUIAR et al., 2006, p. 825). Nesse intervalo de tempo, surgem as iniciativas do Ministério da Educação (MEC) com relação à formação de professores e ao Curso de Pedagogia, ou seja, as Resoluções nº 01 e 02/2002 que instituem Diretrizes para a Formação de Professores.

Em maio de 2006, são publicadas as Diretrizes Curriculares Nacionais (DCN) para o Curso de Pedagogia, com destaque para o perfil do pedagogo, sendo este pautado na docência, como preceitua o artigo $4^{\circ}$ abaixo citado: 
O curso de Licenciatura em Pedagogia destina-se à formação de professores para exercer funções de magistério na Educação Infantil e nos anos iniciais do Ensino Fundamental, nos cursos de Ensino Médio, na modalidade Normal, de Educação Profissional na área de serviços e apoio escolar em outras áreas nas quais sejam previstos conhecimentos pedagógicos. (BRASIL, 2006, p. 2).

O artigo apontado acima denuncia o magistério como função específica do curso de Pedagogia, com atuação tanto na docência, como qualquer ação que envolva o serviço escolar com base na requisição de conhecimentos pedagógicos. Assim, as habilitações Supervisão, Orientação, Administração e Inspeção Educacional, antes campos formativos deste curso, foram extintas e estende ao profissional da pedagogia, um conjunto de funções que abarcam outras áreas, funções estas que abrangem a participação na organização de gestão de sistema e instituições de ensino relacionadas com atividades de planejamento, coordenação, avaliação, produção do conhecimento educacional em contextos escolares e não escolares (LIBÂNEO, 2006).

Assim, as DCN abrem novos horizontes para a formação e atuação profissional. Contudo, para Aguiar et al. (2006), as DCN não apagam as polêmicas sobre a identidade do Curso de Pedagogia, especialmente no que tange à docência. A docência nas DCN-Pedagogia não é entendida no sentido restrito do ato de ministrar aulas. O sentido da docência é ampliado, uma vez que se articula à ideia de trabalho pedagógico, a ser desenvolvido em espaços escolares e não escolares. (AGUIAR et al., 2006),

O desafio de viver a docência em espaços não escolares tem registro legitimado nestas Diretrizes Curriculares, quando em seu artigo art. 5 , inciso IV (BRASIL, 2006) define que:

O egresso do curso de Pedagogia deverá estar apto a: IV - trabalhar, em espaços escolares e não-escolares, na promoção da aprendizagem de sujeitos em diferentes fases do desenvolvimento humano, em diversos níveis e modalidades do processo educativo. (BRASIL, 2006, p. 2, grifo nosso).

A legislação supracitada anuncia os desafios da contemporaneidade para a atuação do/a pedagogia, notadamente, no que concerne a estar apto, de acordo o que determina legislação brasileira (BRASIL, 2002a), em relação ao atendimento pedagógico educacional em espaços escolares e não-escolares, em particular em relação ao direito das crianças e adolescentes, quando hospitalizadas.

Associamo-nos a autores como Fonseca (2003), Matos e Mugiatti (2007) ao avultarem a relevância desse direito, embora reconheçam a complexidade do atendimento em condições de internação. Nessa perspectiva, a formação do/a professor/a, especialmente, em cursos de pedagogia, deve ocupar-se também da educação não escolar, não restrito ao debate acadêmico, mas atentos aos conteúdos do seu projeto formativo, diferentemente do que tem acontecido, até então, ou seja, dar prioridade para as questões que envolvem a escola regular como se fosse o lócus único e específico da prática de tais profissionais. O que não se sustenta de acordo com o que determina a legislação do curso, nem tampouco em função das demandas reais da sociedade.

Nesta perspectiva, o curso de Pedagogia da UFMA, de conformidade com as DCN, tem desenvolvido algumas experiências inclusivas em espaços não escolares, através da extensão universitária, em que o Núcleo de Humanização do HUUFMA em parceria com o Departamento de Educação I da UFMA, em 2007, propiciou a elaboração do projeto de extensão a que vimos nos reportando. Dessa forma, as crianças hospitalizadas naquele hospital vivenciam com alunas do Curso de Pedagogia, as especificidades de concretizar atividades de cunho escolar, envolvendo conteúdos curriculares próprios de sua faixa etária e escolarização. 
OS SABERES DE FORMAÇÃO | Francy S. Rabelo, Silvina P. Silva e Geandra Claúdia S. Santos

A esse respeito Taam (2004, p. 104) chama atenção para a existência de especificidades a serem consideradas, pois o fazer pedagógico no hospital distancia-se do que é realizado na escola. Destaca que,

\begin{abstract}
A criança não vai ao hospital para estudar, ela vai para curar-se de uma doença. Sem dúvida, a aprendizagem de conteúdos curriculares é importante nas internações de longo prazo, refletindo-se na auto-estima da criança e aumentando as chances de um retorno exitoso (ou ingresso) ao (no) sistema escola. Contudo, as questões primordiais a serem enfrentadas dentro de um hospital, são a saúde da criança, o alívio do sofrimento, a forma como a experiência de hospitalização vai ser compreendida. Além disso, a rotina do hospital não se assemelha à da escola, e bem diferentes são as experiências vividas pela criança. Dessa compreensão, resultam objetivos e estratégias diferentes, em alguns pontos, daqueles definidos para o espaço escolar.
\end{abstract}

Verifica-se assim, que lidar com contextos distintos do ambiente escolar não é tarefa fácil para professores/as. A precária formação e a pouca convivência com a realidade dos espaços não escolares justificam dificuldades no enfrentamento das situações com as quais se deparam. A classe hospitalar (FONSECA, 2003), por exemplo, possui ritmo e metodologia próprios; o tempo de internação da criança no hospital distingue-se do atendimento convencional ou emergencial em hospitais, diverso do que acontece no convívio do ambiente escolar. Porém, cabe considerar que a inserção em atividades pedagógicas no contexto hospitalar só tem sentido quando transformadas em tempos de aprendizagem, de construção de saberes e aquisição de novos conceitos, proporcionados pelas ações realizadas nesse ínterim.

As restrições ou limitações encontradas na efetivação e desenvolvimento do trabalho pedagógico na educação hospitalar são várias, uma vez que esses pacientes-alunos se encontram debilitados e angustiados quanto à situação vivida, além de apresentarem com a doença e seus percalços, outro ritmo de aprendizagem e desempenho, mediante a condição de vulnerabilidade a que estão submetidos.

Contudo, as atividades pedagógicas realizadas com alunos hospitalizados devem favorecer a continuidade do processo de escolarização da criança doente, exigindo também de seus/suas professore/as a possibilidade de saber vivenciar as especificidades de uma educação em espaços não escolares. Estar em ambiente tão diferente da escola e conviver com profissionais de outras áreas não deixa de trazer provocações, conforme declaração de uma das egressas, sujeito da pesquisa, sobre essa vivência:

Quando entrei no hospital fiquei ansiosa para saber como eu poderia desenvolver um trabalho pedagógico, como realizá-lo, porque cada dia era um dia diferente, completamente diferente da rotina escolar. Mal estávamos fazendo uma atividade entrava a enfermeira para fazer um procedimento, então aquilo ali é algo que quebrava o momento do trabalho, mas depois continuávamos, contudo apesar daquela quebra, a gente percebia que a criança fazia o procedimento, no intuito de logo depois conseguir voltar às atividades, então o entusiasmo dela me contagiava; aquele contato era muito legal (EB4).

No relato, o sentimento de ansiedade e incerteza, expresso no trecho acima, reforça o convencimento da complexidade das ações docentes em relação à rotina em geral do internamento. Atuar com aluno/s hospitalizado/as demanda também, conhecimentos sobre o uso de medicamentos, ter noção dos diferentes tipos de enfermidades, entre outros aspectos não usuais na prática de uma professora da classe de ensino regular, uma vez que esses conteúdos não fizeram parte dos componentes curriculares de sua formação (GOLDMAN, 2010). 
O diálogo com os profissionais da saúde é de extrema importância para esclarecer conceitos advindos de nomenclaturas desconhecidas do ofício do/a professor/a. Fonseca (2003, p. 46) orienta como passo inicial para ir vencendo essa tensão a leitura do "prontuário tanto para tomar conhecimento da situação de saúde da criança quanto para se informar sobre a evolução e o tratamento".

Conciliar a vida de pacientes hospitalizados com as atividades da rotina escolar suscita várias questões. Motivar para o aprender é uma delas, destacando-se como fator de grande angústia para as professoras. Menezes (2004) enfatiza a necessidade de um novo perfil docente em relação ao exercício de seu ofício no hospital. Ter um conhecimento das ciências da educação, da realidade hospitalar e do internado para atuar nesse espaço é imprescindível, cabendo ao/a professor/a mobilizar o seu repertório de saberes (TARDIF, 2010) para enfrentar os problemas oriundos do fazer docente no hospital.

Os saberes produzidos no fazer-se professor/a na academia, no ambiente de trabalho, na troca de experiências internalizadas como discente, bem como em sua trajetória pré-profissional [...] "têm um peso importante na compreensão da natureza dos saberes, do saber-fazer e do saber-ser que serão mobilizados e utilizados em seguida quando da socialização profissional e no próprio exercício do magistério" (TARDIF, 2010, p. 69). Portanto, a competência deste fazer tem raízes em suas vivências individuais e coletivas, com matriz nos saberes adquiridos e, também produzidos nos contextos de sua prática. O campo de trabalho, as diversas situações enfrentadas cotidianamente são locais de difusão e aquisição de tais saberes.

A promulgação das DCN para o Curso de Pedagogia abalou antigos paradigmas que delineavam um perfil de formação e atuação do/a pedagogo/a restrito ao ambiente da escola. Os espaços não escolares, tais como, empresas, sindicatos, hospitais e outros, ganham status nas diretrizes, nas quais se defendem uma formação do/a pedagogo/a que os prepare para atuarem além dos muros da escola, com a inclusão de conteúdo disciplinar e pedagógico que os habilite a trabalhar em outros espaços que não seja somente o escolar.

Tais questões refletem a necessidade de repensar as propostas curriculares dos cursos de Pedagogia, condição necessária para que as instituições formadoras possam contribuir verdadeira e significativamente para a construção de um novo perfil do/as futuro/as pedagogo/as.

Pimenta (2009, p. 19) destaca como imprescindível a construção de saberes docentes que envolvam a identidade da profissão de professor/a e da:

[...] significação social da profissão; da revisão constante dos significados sociais da profissão; da revisão das tradições. [...]. Do confronto entre as teorias e as práticas, da análise sistemática das práticas à luz das teorias existentes, da construção de novas teorias [...] Assim, como a partir de sua rede de relações com outros professores, nas escolas, nos sindicatos e em outros agrupamentos.

Cabe assim, ponderar que a formação deve dar ênfase ao processo de autoformação, de reelaboração de saberes adquiridos na formação inicial, confrontadas com a realidade, através dos movimentos pedagógicos ou das comunicações de práticas nas quais o/a professor/a se insere, porque reforça um sentimento de pertença e de identidade profissional. Nóvoa (1992, p. 25) assevera em suas reflexões, que "a formação não se constrói por acumulação [de cursos, de conhecimentos ou de técnicas], mas sim através de um trabalho de reflexividade crítica sobre as práticas e de re(construção) permanente de uma identidade pessoal". O ser, o fazer e o tornar-se professor/a não se dão num movimento solitário; ao contrário, são alcançados nos diversos processos formativos, seja individual ou coletivamente, como possibilidade de tornar viva esta identidade pessoal e profissional. 
OS SABERES DE FORMAÇÃO | Francy S. Rabelo, Silvina P. Silva e Geandra Claúdia S. Santos

A ação docente no hospital é uma realidade e vem se tornando paulatinamente mais requisitada. Por este motivo ela deve ser contemplada na formação de pedagogo/as, conforme declara os estudos de Menezes (2004, p. 65), ao afirmar que seja:

\begin{abstract}
[...] necessário preencher lacunas em termos de conhecimento científico sobre diferentes tipos de doenças, procedimentos pedagógicos apropriados para cada criança internada, o preparo para lidar com a situação de morte, buscando-se sempre a contribuição integrada de enfoques com outras áreas do conhecimento necessárias para o trabalho do pedagogo nos hospitais.
\end{abstract}

Os argumentos da autora são considerados de grande valia, embora desafiadores. O diálogo com os demais profissionais da saúde, para suprir a carência de conhecimentos não é próprio do projeto do curso de Pedagogia da UFMA, tampouco de outras universidades. Parceria estreita entre esse/as profissionais da educação e da saúde para que possam se ajudar mutuamente é uma recomendação a ser efetivada. Todavia, não dispomos de modelos ou propostas com essa finalidade. Estes precisam ser elaborados, em consonância com ações docentes vivenciadas em hospital através de projetos, estágios que favoreçam criar uma identidade social, construir um sentimento de pertença, tomar consciência da condição de sujeito social que enxerga o outro nas suas limitações e, acima de tudo, com humildade para que possam juntos realizarem bem suas tarefas.Vejamos a fala de um dos sujeitos da pesquisa:

Na formação inicial é importante conhecer outros espaços, especialmente o hospital, [...],
eu tinha 06 anos de experiência docente na educação infantil, quando fazia pedagogia,
essa experiência no hospital produziu outros conhecimentos, porque hoje faço a diferença.
[...] quando eu chegava ao hospital, era necessário desenvolver toda uma sensibilidade,
conhecer mesmo, escutar, para gente poder entrar no mundo deles, nós tínhamos que
trazê-los para um outro mundo, o mundo da escola, pois não esqueçamos que o hospital
é também um espaço considerado frio para uma criança (EV1).

O depoimento da entrevistada denota que os saberes da experiência advindos de sua prática como professora da Educação Infantil passaram por modificações diversas. Os anos vivenciados em sua atividade docente serviram a uma reavaliação de sua prática, geraram o aparecimento de uma carga de sentimentos aparentemente adormecidos, porém revigorados nesse espaço, frente à fragilidade do sujeito aprendente, alimentando a compreensão de que a pessoa doente também possa cumprir suas tarefas escolares. Ainda sobre os saberes docentes evidenciados nesta experiência, outra egressa se reportou dizendo que os saberes desenvolvidos na ação docente são os que as tornam professoras, porque esta ação é alimentada pelos saberes adquiridos na formação universitária. Por esta razão, a vivência é extremamente importante. Segundo a egressa, é pela vivência "que nos tornamos mais humildes, mais sensíveis, mais humanos, mais solidários, mais companheiros, nos tornamos mais forte em suportar a situação da criança doente [...]" (EV4).

A sensibilidade que a egressa se reporta adveio essencialmente do relacionamento entre aluna/professora e aluno/paciente, o que nos possibilitou também, a compreensão do papel das emoções e dos afetos como um componente essencial da construção do processo de ensino e de aprendizagem. Branco (2008, p. 67) corrobora com essa ideia ao afirmar que, são precisamente "as reações emocionais que devem constituir a base do processo educativo"; haja vista, o saber adquirido na vivência da docência no ambiente hospitalar, antes de lidar com as emoções do outro seja "preciso saber lidar com as nossas; é preciso assumir o que sentimos, para que a ação pedagógica não seja apenas algo que faça sentir melhor, a nós próprios" (TAAM, 2004, p. 28). 
Devemos considerar importante na relação professor/aluno a presença da "amorosidade", da afetividade. Tardif (2010, p. 130) situa a dimensão afetiva como uma das características do trabalho docente, porque "baseia-se em emoções, em afetos, na capacidade não somente de pensar nos alunos, mas, igualmente, de perceber e de sentir suas emoções, seus temores, suas alegrias, seus próprios bloqueios afetivos". Neste sentido, as egressas reconhecem as experiências no âmbito das classes hospitalares como portadoras de aprendizagens significativas para o exercício da docência, pois através de suas próprias experiências no hospital, na relação com a criança internada vivem momentos particulares, "diferentes de tudo o que se encontra habitualmente, sendo registrado como tal em nosso repertório de saberes" (GAUTHIER et al., 1998, p. 32). A sensibilidade destacada, portanto, ao constituir-se como sentimento internalizado integram-se aos seus saberes e são utilizados na sua atuação profissional, destaque na fala seguinte:

\begin{abstract}
Essa relação me ajudou muito na minha volta pra minha sala de aula, eu tive um outro olhar, lá não prestamos tanta atenção de forma individualizada ao aluno, eles nos chamam a atenção do jeito deles. Aqui no hospital foi diferente, eu vi o envolvimento daqueles adolescentes, se tornaram amigos na construção de atividades, o envolvimento deles com as atividades era muito grande, eu com essas ações e o envolvimento que essas crianças me mostraram, me tornei mais sensibilizada, quando voltei pra minha sala de aula eu estava diferente, eu recomendaria para todo o pedagogo passar pela educação não escolar, especialmente o hospital, principalmente para aqueles professores, carregados de sua experiência e acham que não tem mais nada para aprender e nem para contribuir com os alunos (EV3).
\end{abstract}

A formação adquirida com as experiências docentes, em espaços não escolares, aprimora o saber-ensinar, contribuindo para que tais saberes se agreguem aos conhecimentos que envolvem a sua profissionalização. Nesse sentido, nos registros monográficos, uma egressa releva a importância da educação não escolar atrelada à formação inicial, expressando que esta:

[...] tem intuito de oportunizar situações de educação em contextos não escolares. O cenário do hospital está sofrendo transformações através da Pedagogia hospitalar e é possível a criança hospitalizada continuar ou iniciar o seu processo de alfabetização no cenário diferente da escola, no caso, o hospital. (SANTANA, 2011, p. 65).

Do que foi explicitado pelos sujeitos está notadamente presente em suas falas, ao relatarem sobre a importância da formação inicial articulada à educação não escolar no hospital, de que na escola regular, a rotina é conhecida por conta das experiências adquiridas em seu processo formativo, a exemplo dos estágios supervisionados, enquanto que no hospital, esta rotina torna-se diferente por não ser contemplada no seu projeto de formação curricular, como no curso de Pedagogia da UFMA. Tal contato se faz pela extensão universitária e quando este é vivenciado, percebe-se que esta rotina é mais complexa e, portanto, mais lenta a adaptação, o que requer esforço na adaptação dos saberes oriundos da formação profissional e até daqueles advindos da experiência.

A convivência com profissionais de formações diversas ajuda no entendimento sobre o complexo ambiente hospitalar, além da criação dos laços afetivos que se estabelecem na relação dos sujeitos (aluno/paciente e aluna/professora). Esta situação foi referenciada em outro registro monográfico de uma egressa, quando diz que "as ações do pedagogo devem extrapolar conceitos, métodos e teorias pedagógicas quando confrontadas com a realidade, pois exige do profissional mais que seus delineamentos teóricos disponibilizam" (SIMÕES, 2012, p. 60) e estas ações podem prevenir traumas, amenizar sentimentos de insegurança e de angústia junto à criança hospitalizada (ASSIS, 2009). 
OS SABERES DE FORMAÇÃO | Francy S. Rabelo, Silvina P. Silva e Geandra Claúdia S. Santos

As experiências relatadas pelas egressas participantes do estudo demonstram o valor do aprender a ser professora em espaço não escolar, pois no hospital tiveram que se adequar à rotina da instituição, além de ter contato com diálogos científicos, até então desconhecidos, constituídos em saberes que mobilizados na prática pedagógica que dizem respeito a uma perspectiva mais humanizadora do ser professora.

\section{3| CONSIDERAÇÕES FINAIS}

Na finalização deste artigo, esboçamos o entendimento de que o exercício da docência requer dos professores uma formação que incorpore não apenas os debates acerca do conteúdo das disciplinas, do direito e garantia à educação, mas, essencialmente, portadora de saberes que ultrapassem os conhecimentos limitados do fazer restrito aos muros da escola. A prática educativa demanda saberes que independem de opção política, mas de uma formação que disponha de subsídios teórico-práticos para o exercício da docência em espaços escolares e não escolares.

No contexto atual, com a iniciativa de inclusão das atividades pedagógicas no atendimento em classes hospitalares aponta o propósito de que, mesmo hospitalizado, o/a aluno/a-paciente mantenha ligação com o mundo lá fora, potencializando suas relações sociais, ampliando seu vínculo familiar, a fim de garantir a continuidade de sua escolarização, bem como a redução das consequências da hospitalização. Ao mesmo tempo em que demanda dos profissionais da educação enfrentar os desafios próprios desse fazer diferenciado.

Atender às necessidades fundamentais do desenvolvimento infantil em situação de moléstia exige ação conjugada hospital-escola baseada numa proposta de educação que possa não exclusivamente ter importância no que se refere ao atendimento pedagógico, mas, também, na promoção de atividades lúdicas promotoras da eficácia do desenvolvimento psíquico, afetivo e cognitivo da criança internada.

Para tanto, é necessário atentar que com o advento das classes hospitalares ampliou-se o nível de exigências da formação para a realização de atividades educativas no atendimento hospitalar. É necessário, pois, que seja incluído no debate como conteúdo do processo de formação docente, o que ocorre, principalmente, com a oferta em Cursos de Pedagogia de uma matriz curricular que contribua para que seus futuros profissionais alcancem as novas exigências demandadas pelo seu campo de trabalho e para o atendimento e fortalecimento de uma educação, na perspectiva das Classes Hospitalares e/ou de outras áreas dos espaços não escolares, cenário de atuação desses docentes. O estudo aponta a possibilidade de lidar com o enfrentamento dos desafios inerentes a esse atendimento se vincularmos aos processos formativos dos docentes, a possibilidade de prepará-los para que possam desenvolver a condição de sujeitos produtores de um saber diferenciado daqueles que envolvem prioritariamente a atuação na escola, pois tal preparo se distancia e diferencia-se de uma sala de aula regular.

Cumpre ressaltar que, apesar das iniciativas do Ministério da Educação (BRASIL, 2002a) e da Resolução (BRASIL, 1995) que determina a garantia do direito à escolarização das crianças hospitalizadas, ainda são incipientes, as discussões acerca de tal direito no Estado do Maranhão. Desconhecemos, portanto, qualquer discussão entre os cursos de formação de professores, ou de pedagogia para efetivação da referida Classe, a não ser por projetos de iniciativas individuais, como é o caso do projeto referenciado neste trabalho.

É possível afirmar que a atuação do/a pedagogo/a com a participação na experiência desenvolvida no hospital, objeto destas análises, se inscreve como possibilidade de produção de um saber distinto do da escola, fundamental para o enfrentamento de desafios pedagógicos exigidos para o trabalho com os pacientes de classes hospitalares. 
OS SABERES DE FORMAÇÃO | Francy S. Rabelo, Silvina P. Silva e Geandra Claúdia S. Santos

Mormente, reforçamos a ideia de que os processos formativos são responsáveis por oferecer subsídios teórico-práticos para que o/as pedagogo/as lidem com situações adversas as que acontecem nos espaços escolares, mediados pela provocação em função de que devam se dedicar para construírem e reconstruírem conhecimentos, conforme a necessidade de seu fazer docente.

A partir do contato com experiências diferenciadas das que vivenciam na escola, entendemos, que sejam propícias à produção e revisão de saberes para que possam atuar em ambientes prenhes de práticas desconhecidas de seu convívio docente regular. Cabe, portanto, reafirmar a necessidade de revisão curricular dos cursos de Pedagogia, uma vez que suas Diretrizes Curriculares Nacionais apontam para novas demandas de atuação.

Há o reconhecimento, por parte dos sujeitos desta pesquisa que os saberes docentes devam entrelaçar os saberes da experiência, curriculares, disciplinares e todos aqueles alimentados na academia, necessários ao exercício do ser professor, os quais agregam os saberes da formação profissional.

O envolvimento com a classe hospitalar possibilitou maior humanização e comprometimento dos sujeitos desta pesquisa, as quais desenvolveram maior respeito em relação às diferenças culturais, assim como das condições de vida dos sujeitos que estão inseridos no processo educativo, em contextos específicos, como um hospital.

Torna-se necessário que o/as pedagogo/as ampliem uma escuta sensível a partir das histórias de vidas dos sujeitos, seus gestos, suas palavras e seus comportamentos, estando atentos às modificações que se sucedem nas reações da hospitalização e da doença, conscientes de que a gestão da sala de aula hospitalar ultrapassa os saberes da ação pedagógica em classes regulares de ensino.

Os saberes necessários ao ensino no hospital ao serem reelaborados e construídos pelas alunas/professoras em confronto com suas experiências e práticas e com os diversos sujeitos do hospital, são incorporados em sua prática, no processo de formação pessoal e profissional, trazendo modificações para o seu trabalho docente. 


\section{Referências}

AGUIAR, M. A. da S. et al. Diretrizes curriculares do curso de pedagogia no Brasil: disputas de projetos no campo da formação do profissional da educação. Educação e Sociedade, Campinas, v. 27, n. 96 - Especial, p. 819842, out. 2006. Disponível em: <http://www.scielo.br/pdf/ es/v27n96/a10v2796.pdf|>. Acesso em: 16 set. 2016.

ANDRÉ, M. E. D. A. de. Estudo de caso em pesquisa e avaliação educacional. Brasília: Liber Livro Editora, 2005.

ANFOPE. Políticas nacionais de formação no sistema nacional de educação: base nacional comum para a educação básica e a formação de professores. In: ENCONTRO NACIONAL DA ANFOPE, 17., 2014, Brasília, DF. Documento final... Brasília, DF: ANFOPE, 2014.

ASSIS, W. de. Atendimento pedagógico-educacional em hospitais: da exclusão à inclusão social/escolar. 2009. 123f. Dissertação (Mestrado em Educação) - Universidade de São Paulo, São Paulo, 2009.

BRANCO, R. F. G. y R. Capacitação de professores de classe hospitalar em relação professor-aluno/paciente na perspectiva balintiana. 2008. 180f. Tese (Doutorado em Educação) - Universidade Federal de Goiás, Goiânia, 2008.

BRASIL. Lei de diretrizes e bases da educação nacional: lei $n^{\circ}$ 9.394, de 20 de dezembro de 1996, que estabelece as diretrizes e bases da educação nacional. 5. ed. Brasília: Câmara dos Deputados; Coordenação Edições Câmara, 2010. 60 p. (Série Legislação, n. 39).

Ministério da Educação. Secretaria de Educação Especial. Classe hospitalar e atendimento pedagógico domiciliar: estratégias e orientações. Brasília, DF: MEC; SEESP, 2002a.

Resolução CNE/CP n 1, de 18 de fevereiro de 2002. Institui as diretrizes curriculares nacionais para a formação de professores da educação básica, em nível superior, curso de licenciatura, de graduação plena. Diário Oficial da União, Brasília, DF, 09 abr. 2002b. Seção 1, p. 31.

Resolução CNE/CP n² 2, de 19 de fevereiro de 2002. Institui a duração e a carga horária dos cursos de licenciatura, de graduação plena, de formação de professores da Educação Básica em nível superior. Diário Oficial da União, Brasília, DF, 4 mar. 2002c. Seção 1, p. 9.

Ministério da Educação. Secretaria de Educação Especial. Diretrizes nacionais para a educação especial na educação básica. Brasília, DF: MEC; SEESP, 2001a.
Ministério da Educação. Secretaria de Educação Especial. Política nacional de educação especial. Brasília, DF: MEC; SEESP, 1994.

Ministério da Educação. Secretaria de Educação Especial. Política nacional de educação especial na perspectiva da educação inclusiva. Brasília, DF: MEC; SEESP, 2008.

. Resolução CONANDA n 41, de 13 de outubro de 1995. Aprova em sua íntegra o texto oriundo da Sociedade Brasileira de Pediatria, relativo aos direitos da criança e do adolescente hospitalizados. Diário Oficial da União, Brasília, DF, 17 out. 1995. Seção 1, p.16.319-16.320.

Resolução CNE/CEB n² 2, de 11 de setembro de 2001. Institui Diretrizes Nacionais para a Educação Especial na Educação Básica. Diário Oficial da União, Brasília, DF, 14 set. 2001b. Seção 1E, p. 39-40.

Resolução CNE/CP n 1, de 15 de maio de 2006. Institui diretrizes curriculares para o curso de graduação em pedagogia, licenciatura. Diário Oficial da União, Brasília, DF, 16 maio 2006. Seção 1, p. 11.

FONSECA, E. S. Atendimento escolar no ambiente hospitalar. São Paulo: Memnon, 2003.

FONTES, R. S. Da Classe hospitalar à pedagogia hospitalar: a educação para além da escolarização, Linhas, Florianópolis, v. 9, n. 1, p. 72-92, jan./jun. 2008.

GAUTHIER, C. et al. Por uma teoria da pedagogia: pesquisas contemporâneas sobre o saber docente. Itujuí, RS: UNIJUÍ, 1998.

GOLDMAN. F. de O. Saberes para atuação docente hospitalar: um estudo com os pedagogos que atuam nos hospitais de Santa Catarina. 2010. 207f. Dissertação (Mestrado em Educação)- Universidade do Vale do Itajaí, Itajaí-SC, 2010.

LIBÂNEO, J. C. Diretrizes curriculares da pedagogia: imprecisões teóricas e concepção estreita da formação profissional de educadores. Educação e Sociedade, Campinas, v. 27, n. 96, p. 843-876, out. 2006. Disponível em:<http://www.scielo.br/pdf/es/v27n96/a11v2796.pdf/>. Acesso em: 15 set. 2016.

MATOS, E. L. M.; MUGGIATI, M. M. T. de F. Pedagogia hospitalar: a humanização integrando educação e saúde. Petrópolis, RJ: Vozes, 2007.

MENEZES, C. V. A. de. A necessidade da formação do pedagogo para atuar em ambiente hospitalar: um estudo de caso em enfermarias pediátricas do hospital de clínicas da UFPR. 2004. 131f. Dissertação (Mestrado em Engenharia da Produção)- Universidade Federal de Santa Catarina, Florianópolis, 2004. 
OS SABERES DE FORMAÇÃO | Francy S. Rabelo, Silvina P. Silva e Geandra Claúdia S. Santos

NÓVOA, A. (Org.). Os professores e sua formação. Lisboa: Dom Quixote, 1992.

PIMENTA, S. G. Formação de professores: identidade e saberes da docência. In: PIMENTA, S. G. (Org.). Saberes pedagógicos e atividade docente. São Paulo: Cortez, 2009.

RABELO, F. S. Educação não escolar e saberes docentes na formação do pedagogo: análise de uma experiência no espaço hospitalar. 2014. 184f. Dissertação (Mestrado em Educação) - Universidade Estadual do Ceará, Fortaleza, 2014.

SANTANA, L. A. Pedagogia hospitalar: uma contribuição saudável no processo de alfabetização de crianças hospitalizadas no Hospital Materno Infantil. 2011. 74f. Monografia (Curso de Pedagogia) - Universidade Federal do Maranhão, São Luís, 2011.
SIMÕES, K. C. R. Educação em saúde: uma análise da leitura mediada como prática pedagógica em ambiente hospitalar. 2012. 66f. Monografia (Curso de Pedagogia) Universidade Federal do Maranhão, São Luís, 2012.

STAKE, R. E. A arte da investigação com estudos de caso. Tradução Ana Maria Chaves. Lisboa: Fundação Calouste Gulbenkian, 2007.

TAAM, R. Pelas trilhas da emoção: a educação no espaço da saúde. Maringá: Eduem, 2004.

TARDIF, M. Saberes docentes e formação profissional. Petrópolis, RJ: Vozes, 2010.

YIN, R. K. Estudo de caso: planejamento e métodos. 4. ed. Porto Alegre: Bookman, 2010. 